\title{
Guillain-Barré syndrome associated with Covid-19: A close relationship or just a coincidence? (Review)
}

\author{
ADINA STOIAN $^{1}$, RODICA BĂLAȘA ${ }^{2}$, BIANCA LIANA GRIGORESCU $^{1}$, SMARANDA MAIER $^{2}$, \\ SEBASTIAN ANDONE ${ }^{3}$, IULIU GABRIEL COCUZ ${ }^{1}$, ZOLTAN BAJKO $^{2}$, \\ CRISTIAN RARES FILEP ${ }^{4 *}$ and MIRCEA STOIAN ${ }^{* *}$
}

\author{
Departments of ${ }^{1}$ Pathophysiology and ${ }^{2}$ Neurology, 'George Emil Palade' University of Medicine, Pharmacy, \\ Science and Technology; ${ }^{3}$ Department of Neurology, 1 st Neurology Clinic, Mures County Clinical Emergency Hospital; \\ ${ }^{4}$ Department of Interventional Radiology, Mures County Clinical Emergency Hospital; \\ ${ }^{5}$ Department of Anesthesiology and Intensive Therapy, 'George Emil Palade' University of Medicine, Pharmacy, \\ Science and Technology, 540136 Targu Mures, Romania
}

Received March 30, 2021; Accepted April 29, 2021

DOI: $10.3892 / \mathrm{etm} .2021 .10348$

\begin{abstract}
Several neurological complications affecting the central and peripheral nervous system were described secondary to COVID-19 infection such as hyposmia, headache, nausea, impaired consciousness, psychosis, neurocognitive syndromes
\end{abstract}

Correspondence to: Dr Zoltan Bajko, Department of Neurology, 'George Emil Palade' University of Medicine, Pharmacy, Science and Technology, Marinescu Gh 50, 540136 Targu Mures, Romania E-mail: bzoltan2003@yahoo.com

*Contributed equally

Abbreviations: COVID-19, coronavirus disease 2019; SARS-CoV-2, severe acute respiratory syndrome 2; WHO, World Health Organization; SARS, severe acute respiratory syndrome; CNS, central nervous system; PNS, peripheral nervous system; GBS, Guillain-Barré syndrome; NCV, nerve conduction studies; AIDP, acute inflammatory demyelinating polyradiculoneuropathy; AMAN, acute motor axonal neuropathy; AMSAN, acute motor sensory axonal neuropathy; MFS, Miller Fisher syndrome; APC, antigen-presenting cells; IL, interleukin; INF- $\gamma$, interferon- $\gamma$; TNF- $\alpha$, tumor necrosis factor- $\alpha$; BNB, blood nerve barrier; $C$. jejuni, Campylobacter jejuni; TGF- $\beta$, transforming growth factor- $\beta$; EAN, experimental autoimmune neuritis; Th1, $\mathrm{T}$ helper 1 cell; IgG, immunoglobulin $\mathrm{G}$; CSF, corticospinal fluid; ICU, intensive care unit; ACE2, angiotensin-converting enzyme 2; SIADH, syndrome of inappropriate antidiuretic hormone secretion; $\mathrm{CT}$, computed tomography; MRI, magnetic resonance imaging; $\mathrm{BBB}$, blood brain barrier; PCR, polymerase chain reaction; RT-PCR, reverse transcription-PCR method; RNA, ribonucleic acid; IVIg, intravenous immunoglobulins; TPE, therapeutic plasma exchange; CMV, cytomegalovirus; EBV, Epstein Barr virus; HIV, human immunodeficiency virus; M. pneumoniae, Mycoplasma pneumoniae, H. influenza, Hemophilus influenzae; MERS, Middle East respiratory syndrome; CIDP, chronic inflammatory demyelinating polyneuropathy

Key words: Guillain-Barré syndrome, COVID-19, neurological complications, AMAN, tetraparesis, SARS-CoV-2 and even cerebrovascular accidents. The mechanism of these complications is not fully understood, but heterogenous mechanisms such as cytokine storm, secondary hypercoagulability and direct neurotropism of the virus are thought to be involved. Guillain-Barré syndrome is a heterogeneous disease that frequently follows a bacterial or viral infection. During the ongoing SARS-CoV-2 pandemic, several isolated case reports and case series have suggested an association between this viral infection and the occurrence of Guillain-Barré syndrome. The main mechanism of Guillain-Barré syndrome is probably post-viral dysregulation of the immune system generated by SARS-CoV-2. The clinical characteristics and disease evolution seem to be similar to those observed in Guillain-Barré syndrome secondary to other etiologies. The aim of the present review is to summarize the relevant literature regarding SARS-CoV-2-related Guillain-Barré syndrome.

\section{Contents}

1. Introduction

2. Epidemiology

3. Pathophysiology

4. Characteristics of patients with COVID-19 and GBS

5. Discussion

6. Conclusions

\section{Introduction}

The coronavirus disease 2019 (COVID-19) pandemic constitutes a persistent threat caused by the novel single-stranded RNA $\beta$ coronavirus, severe acute respiratory syndrome 2 virus (SARS-CoV-2). It is now widely acknowledged that many organs are involved in COVID-19 in different ways, including the central and peripheral nervous system (1). According to the World Health Organization (WHO) on September 25, 2020, there were $32,110,656$ confirmed cases and 980,031 deaths globally (1). 
Neurological manifestations were among the last identified, as initial attention focused on the severe acute respiratory syndrome (SARS) and digestive symptoms, with the virus appearing, initially, to spare the nervous system. Neurological symptoms were soon reported with isolated case reports appearing first. Data were published in the literature regarding neuromuscular complications and neurological manifestations which were frequently described among hospitalized patients with COVID-19 $(1,2)$. A wide variety of neurological symptoms are now reported in neurological complications that accompany the viral infection, including cerebrovascular disease, encephalopathy and encephalitis, seizures, movement disorders, neuropsychiatric disorders, myopathy, cranial and peripheral neuropathies $(3,4)$. Neurologic manifestations may be the result of virus neurotropism which can reach the central nervous system (CNS) through cranial nerves and olfactory pathways or via circulation, while damage to the peripheral nervous system (PNS) is likely the result of a parainfective autoimmune reaction $(3,5)$.

Successive case reports describing the association between Guillain-Barré syndrome (GBS) and SARS-CoV-2 infection have raised the issue of a possible link between the two.

\section{Epidemiology}

GBS is a group of autoimmune diseases with acute/subacute evolution characterized by progressive and ascending motor deficit in the limbs, often with sensory, cranial nerve involvement $(4,6)$. Depending on the clinical presentation, underlying pathology, and nerve conduction velocity (NCV) results, GBS is divided into several subtypes, the most common of which is acute inflammatory demyelinating polyradiculoneuropathy (AIDP), the axonal variant acute motor axonal neuropathy (AMAN) and acute motor sensory axonal neuropathy (AMSAN) which share a similar pathogenesis and have a worse prognosis $(7,8)$, as well as Miller Fisher syndrome (MFS) - characterized by ataxia, areflexia, and ophthalmoparesis. Other less common variants are Bickerstaff brainstem encephalitis, the pharyngeal-cervical-brachial variant, and pan-dysautonomia (8).

The incidence in the general population is 1 or $2 / 100.000$ individuals per year (9). Toscano et al reported 5 cases of GBS occurring in 1,000-1,200 patients with COVID-19 in Northern Italy, suggesting a higher incidence than in the general population and raising the possibility of an etiological connection between GBS and SARS-CoV-2 (10). Monitoring of the incidence of GBS cases under the conditions of the SARS-CoV-2 pandemic was performed in Friuli Venezia-Giulia, Italy, where 8 cases were reported in the months of March and April with a monthly incidence of $0.65 / 100.000$ compared to $0.12 / 100.000$ patients in the same months of previous years, suggesting an unusual cluster (11). In Spain in the region Castilla-La Mancha a register of patients with COVID-19 who had neurological manifestations was established, named ALBACOVID registry. Of the 841 such patients, only one was diagnosed with AIDP form of GBS which appeared in the recovery phase of the viral infection (3).

\section{Pathophysiology}

In AIDP, antigen-presenting cells (APC) which can be macrophages or dendritic cells, the antigen, which is a bacterial protein epitope, is processed and presented to T cells which become activated and release cytokines that activate endoneurial macrophages $(6,12)$. Both $\mathrm{T}$ and $\mathrm{B}$ cells are involved, with T cells helping B cells to transform into plasma cells via interleukin-4 (IL), IL-6, interferon- $\gamma$ (INF- $\gamma$ ), and tumour necrosis factor- $\alpha$ (TNF- $\alpha)$. These plasma cells produce antibodies that cross damaged blood-nerve barrier (BNB) and bind with components of myelin, Schwann cells, fix the complement, and produce macrophage-mediated dissolution of myelin $(6,12)$.

In the motor subtype AMAN of GBS, different types of antibodies are directed against peripheral nerve gangliosidelike GM1, GM1b, GD1a, and GalNAc-GD1a that are present on the motor axolemma at the level of Ranvier nodes. This form is characterized by few or no inflammatory infiltrates and a mechanism of molecular mimicry between ganglioside-like epitopes contained in the bacterial wall of pathogens such as Campylobacter jejuni (C. jejuni) and peripheral nerve gangliosides is presumed. The AMSAN subtype shares a similar mechanism and anti-GM1 and GD1 antibodies are present. The B cells are stimulated and produce antibodies that cross-react with axolemmal antigens, produce complement fixation, and activate macrophages to invade the peri-axonal space which may produce a conduction block or cause axonal degeneration $(6,12)$.

Cytokines are considered important mediators in the inflammatory process having a crucial role in activating and differentiating immune cells such as T lymphocytes, B lymphocytes and macrophages and seem to play an important role in the pathophysiology of GBS (13-15).

A number of studies have shown a high level of TNF- $\alpha$, INF- $\gamma$, IL-6, and IL-10 in patients with GBS when compared to healthy controls $(13,16,17)$. Sun et al performed a systematic review of medical literature on blood cytokines in patients with GBS compared to healthy controls and found an increased blood level of inflammatory cytokines INF- $\gamma$, TNF- $\alpha$, IL-1 $\beta$, IL-4, IL-6, IL-17, and CRP (13). However, results of that meta-analysis did not reveal a significant association between IL-10 and transforming growth factor- $\beta$ (TGF- $\beta$ ) and GBS (13). By contrast, Nyati and Prasad demonstrated that patients with the progressive phase of GBS have increased blood levels of TNF- $\alpha$ and IL-1 $\beta$ compared to healthy individuals (12).

The role of cytokines was demonstrated also in the pathogenesis of experimental autoimmune neuritis (EAN) (12). The cytokines in GBS were produced by mononuclear cells or Schwann cells in AIDP and by macrophages in AMAN and AMSAN (12). In addition, cytokine storm from COVID-19 may induce disruption of the BNB, with immune cells able to infiltrate it and affect myelin and Schwann cells.

Infiltrating $\mathrm{T}$ cells in the peripheral nerves produce an increased amount of TNF- $\alpha$ which further promotes T-cell differentiation, affecting the myelin and glycolipid synthesis and having a toxic effect on myelinated fibres, leading to demyelination $(12,13,18)$.

INF- $\gamma$, having a pro-inflammatory role is produced mainly by T-helper 1 cells (Th1) and activates macrophages and endothelial cells, activates B cells and promotes their transformation into plasma cells. In addition, INF- $\gamma$ enhances the antigen-presenting property of the macrophages and the production of other inflammatory cytokines such as IL-1 $\beta$, 
Il-6 and TNF- $\alpha$ (12). Increased levels of IL-1 $\beta$, IL-6, TNF- $\alpha$ and INF- $\gamma$ were correlated with the acute phase of the experimental EAN in rats, while in the recovery phase elevated levels of TGF- $\beta$, IL- 4 and IL-10 were observed $(12,19,20)$. The role of IL-10 remains contradictory: The increased expression downregulates the mediators of neuroinflammation and is considered responsible for modulating the inflammatory response and reducing Th1 cytokine synthesis $(12,19,20)$.

High plasma levels of inflammatory cytokines (IL-1 $\beta$, INF- $\gamma$, TNF- $\alpha$, IL-4, IL-10) are characteristic of rapid viral replication. The neutralizing antibodies (anti-S protein $1 \mathrm{gG}$ ) have been shown to produce tissue injury in different organs, especially the lungs. The presence of elevated immunoglobulin $\mathrm{G}(\operatorname{IgG})$ and oligoclonal bands in corticospinal fluid (CSF) may function as a virus clearer but may also induce a harmful effect (21-23). The increased level of circulating cytokines helps maintain lymphopenia. For example, TNF- $\alpha$ may induce T-cell apoptosis by interacting with TNFR1 receptors located on the aged T cells. IL-6 has both pro- and anti-inflammatory properties and has a role in maintaining chronic inflammation while IL-10 is capable of inducing T-cell exhaustion and preventing T-cell proliferation. The depletion of $\mathrm{T}$ lymphocytes reduces the cellular immune response and favours viral replication (24).

The autopsy findings in COVID-19 patients have an aberrant activation of macrophages, which is also known as macrophage activation syndrome (25).

In COVID-19 patients, especially those requiring intensive care unit (ICU) care, the total number of T cells, specifically $\mathrm{CD}^{+}$and $\mathrm{CD} 8^{+} \mathrm{T}$ cells, is reduced, and their number is inversely correlated with the serum level of TNF- $\alpha$, IL-6, IL-10. This is the so-called 'cytokine storm' that is believed to be responsible, alongside direct viral infection and depletion of $\mathrm{CD}^{+}$and $\mathrm{CD} 8^{+} \mathrm{T}$ cells, for pulmonary epithelial cell injury (21). A similar mechanism may also act on PNS.

It is presumed that the source of cytokines in the peripheral blood is lung macrophages; however, infected neurons are also potentially the source of IL-6, as in the case of a transgenic mouse model of SARS-CoV-2 (26).

A number of immune responses including macrophage and complement activation as well as T-cell mediated immunity were suggested to explain the onset of GBS $(6,13)$ associated with COVID-19. GBS and its variants are presumed to be post-infectious, probably immune-mediated complications of SARS-CoV-2 infection $(8,12,13)$.

The virus binds to angiotensin-converting enzyme 2 (ACE2) receptor to access the human cells. These receptors were reported to be present in endothelial smooth muscle cells from the brain, glial cells, and neurons $(21,27,28)$. The spike protein of SARS-CoV-2 contains a polybasic cleavage site that is responsible for increased transmissibility $(21,29)$. ACE2 is expressed in the cerebral cortex, digestive tract, gall bladder, kidney, lung alveolar cells, testis, and adrenal gland (21,30). The aforementioned findings therefore suggest the potential harm of SARS-CoV-2.

\section{Characteristics of patients with COVID-19 and GBS}

Cranial nerve involvement is now well-known, with anosmia and taste disturbances proving that COVID-19-associated neuropathies are not confined only to the peripheral nervous system $(4,31,32)$. Another report regarding the involvement of the cranial nerves is a recently published case of a 61-year-old male patient in whom, 10 days after the onset of fever and respiratory symptoms, facial diplegia occurred and was treated with low doses of oral prednisone followed by improvement on both sides after two weeks. The authors supposed that SARS-CoV-2 infection may have triggered the neurological complication (33).

The first case of GBS in the context of COVID-19 was reported on 1 April, 2020 from Wuhan by Zhao et al in a 61-year-old woman in whom neurological symptoms began 7 days before the diagnosis of COVID-19 (34). However, it is worth noting that at admission the patient had lymphocytopenia and thrombocytopenia suggesting a pre-existing SARS-CoV-2 infection (34). Then came reports of cases with GBS and COVID-19 that shared comorbidities such as diabetes mellitus which was initially thought to be responsible for the neurological symptoms $(35,36)$. Tiet and AlShaikh reported a patient from UK who developed GBS three weeks after the onset of infectious symptoms, suggesting a post-infectious complication (37). Toscano et al reported 5 cases of GBS developed in the context of COVID-19, 5-10 days post-infection (10).

A group of Pittsburgh authors reported the case of a 72-year old patient who, 7 days prior to neurological onset, had diarrhoea, chills without fever followed by paraesthesias and motor deficit with ascending evolution up to a severe degree (1/5 MRC in upper limbs and 0/5 MRC in lower limbs). Four days after being diagnosed with the AIDP form of GBS, he developed severe dysautonomia with hypotension alternating with hypertension and bradycardia. On the 8th day, he developed inappropriate antidiuretic hormone secretion syndrome (SIADH). The CSF examination did not reveal any anomalies and was negative for infections but his nasopharyngeal swab for SARS-CoV-2 infection was positive. His brain computed tomography (CT) scan was normal and magnetic resonance imaging (MRI) could not be performed because of an incompatible transplant (38).

Dysautonomia as described in COVID-19 patients may be the result of small unmyelinated fiber involvement, but we cannot exclude a central origin (3). Dysautonomia manifested itself in up to $20 \%$ of patients as unstable blood pressure or resistant to treatment hypertension, gastroplegia, and paralytic ileus, and urinary retention (39).

There are a series of case reports presenting patients with acute GBS or MFS, most of them with normal CSF analysis, suggesting that SARS-CoV-2 does not cross the blood-brain barrier (BBB) but instead a post-infectious immune-mediated process may be involved $(6,7,21)$.

Velayos Galán et al (40) and Virani et al (41) observed an interval of $\sim 10$ days between the onset of respiratory symptoms and the first manifestations of GBS. A literature review regarding the neurological manifestations and complications in COVID-19 reported cases with GBS that tested positive for SARS-CoV-2. In some cases, the positive tests preceded the onset of GBS, other times they were initially negative and later positive $(10,39)$. Toscano et al reported 5 cases of GBS developing in the context of COVID-19, 5-10 days post-infection (10). 
A recently published review included 24 patients aged 20-76 years with male predominance 2:1 (8). As in other reviews or isolated case reports, in most situations, the onset of GBS occurred after the clinical manifestations of COVID-19 with an average latency of 9.6 days (between 3 and 23 days). In most patients listed in this review, as in the case reports identified by a search of the medical literature, 14 patients presented AIDP, 7 had the axonal form and 3 patients were diagnosed with MFS (8). Uncini et al consider AIDP to be the most common subtype at up to $80 \%$ occurrence, while the axonal subtypes AMAN and AMSAN account for approximately $14 \%$ (39).

Uncini et al conducted a systematic review that included articles published up to July 6th.2020, and reported 42 patients identified with GBS associated with SARS-CoV-2 infection (39). The mean age of the patients was 57.5 years and the majority were men (64.3\%). Most reported cases were from Europe (79.4\%), and especially from Italy (30.9\%) (39). The diagnosis of SARS-CoV-2 preceded the onset of GBS in $38.1 \%$ of patients, in $50 \%$ of patients the diagnosis was made during hospitalization for GBS and only in two cases was it made retrospectively by serology (39). The time interval between the diagnosis of COVID-19 and GBS reported by Uncini et al was 11.5 days, almost 2 days longer than that reported by Finsterer et al (8) and in $26.2 \%$ of patients, the symptoms of viral infection disappeared before the onset of GBS (39). Infections commonly reported to be associated with GBS were not investigated in all the patients and were excluded in only 7 patients (39).

The temporal relationship between GBS and viral or bacterial infections with a chronological sequence is widely accepted and was reported in humans in previous pandemics (33). As in most reported cases, GBS occurs $\sim 10$ days after viral infection, a causal mechanism is quite likely. We found few cases in which neurological symptoms developed before the viral infection and it is possible that they evolved unnoticed or with minor clinical signs (sore throat, sub febrilities) that did not attract the patients' attention $(34,42)$. COVID-19 may be asymptomatic or oligosymptomatic and the 14-day incubation period makes it difficult to establish a chronological relationship between the SARS-CoV-2 infection and GBS $(39,43)$.

Wang et al (44) reported in their review that polymerase chain reaction (PCR) tests from CSF were negative in all cases, and aseptic neuroinflammation seems to be related to COVID-19 GBS. One hypothesis would be that the cytokine storm secondary to systemic inflammation produces permeabilization and disrupts $\mathrm{BBB}$ and that the overactivation and maladaptive inflammatory responses of the immune system may be responsible for this process $(21,44)$.

A survey was carried out on 58 hospitalized COVID-19 patients with a median age of 63 years, 7 of which had a CSF examination but none of whom had detectable SARS-CoV-2 RNA according to the reverse transcription-PCR method (RT-PCR) and usually, pleocytosis was absent (45). Direct infection and damage of peripheral nerves caused by SARS-CoV-2 has been reported; however, in other cases, CSF examination was negative for viral infection, suggesting the existence of a classic post-infective pattern (32). Similar data were found by Uncini et al in a retrospective study: In $85.7 \%$ of all cases CSF evaluation was performed and $77.8 \%$ of the examined cases presented cyto albumin dissociation. None of the 25 cases in which the search for viral ribonucleic acid (RNA) in CSF was performed was positive (39).

Most of the cases reported had cyto albumin dissociation, negative PCR for SARS-CoV-2 in CSF $(8,10,37)$, positive results being associated with encephalitis with SARS-CoV-2 (46).

One argument against the causal relationship is that SARS-CoV-2 was not isolated from the CSF of the patients with GBS. The mechanism leading to the development of neurological symptoms is not known yet, but we can presume an immune-mediated mechanism involving, similarly to AIDP, molecular mimicry between shared epitopes on the surface of the virus and the nervous membranes in the context of dysregulated immune response with cytokine storm $(8,47)$.

Given the temporal association between these diseases, a causal relationship between GBS and SARS-CoV-2 infection is presumed but, in most cases, no direct invasion of the nerve or nerve roots by the virus has been demonstrated, with the CSF examination being negative for viral infection (35).

Approximately one-third of the patients with GBS associated with COVID-19 required mechanical ventilation, a higher number than data from other studies (6) with GBS cases, suggesting an interaction between pneumonitis with hypoxia and weakness of respiratory muscles, which aggravates the condition of these patients $(4,8)$. Uncini et al reported similar data, with one-third of the patients having respiratory failure and $85.7 \%$ of them needing mechanical ventilation (39).

Associated GBS to COVID-19 treatment consisted mainly of intravenous immunoglobulins (IVIg) and therapeutic plasma exchange (TPE) according to previous guidelines and reports $(6,7,48)$, to which various antiviral treatment regimens have been associated and in some cases ICU support. The improvement was partial but not in all cases, $62 \%$ had relief of symptoms in the short term as identified by Uncini et al (39). The treatment administered in the mentioned cases was the one already established in the treatment of GBS with other aetiologies than the infection with SARS-CoV-2, but the evolution of motor deficit was not optimal in the short term $(4,37,39,49)$.

Regarding treatments for viral infection, Uncini et al reported that of the 42 patients with GBS and SARS-CoV-2 infection evaluated, 7 received azithromycin alone or in combination with hydroxychloroquine, 2 patients received steroids and the rest received hydroxychloroquine and/or antiretroviral drugs (lopinavir and ritonavir) alone or in combination (39). Antiretroviral drugs and hydroxychloroquine are rarely associated with an increased risk of peripheral neuropathy (39).

The majority of patients, 21 of the 24 patients included in a previous review, also received IVIg; one received additional TPE, one received corticosteroids, and 2 recovered spontaneously (8). Male gender and elderly patients seemed to be increasinly affected as compared to the younger generation (8). IVIg treatment seems to have been preferred for GBS associated with COVID-19 compared to other therapeutic approaches, in some situations with a favourable response $(4,37,39,49,50)$.

Electrophysiological studies demonstrated reduced nerve conduction velocities, delayed or absent $F$ wave, and attenuation of action potential amplitude, suggesting demyelination or axonal polyneuropathy. The NCS showed the presence both 
of AIDP (which was more frequent) and the axonal subtypes of GBS (21).

Antiganglioside antibodies were not constantly sought and only one patient with MFS showed IgG to GD1b according to Uncini et al (39). The lack of extensive testing of antiganglioside antibodies is a limiting factor in the reported cases. For cell membrane binding, the SARS-CoV-2 spike protein may interact with GalNAc residue of peripheral nerve GM1 gangliosides and an immune cross-reaction is possible leading to a post-infectious neuropathy $(39,51)$. However, antiganglioside antibodies have rarely been reported in GBS from COVID-19, making this hypothesis unlikely (39).

Other described changes in correlation with clinical manifestations were nerve root enhancement in MRI $(21,52)$. MRI of the spine was performed in some cases and revealed cervical meningeal enhancement, thickening of the nerve roots and cranial nerves in up to $40 \%$ of patients (39), but in GBS, enhancement of spinal roots is described and may spread to the cauda equina which is indicative for a $\mathrm{BNB}$ breakdown $(32,53)$.

\section{Discussion}

GBS is considered an autoimmune process triggered in two-thirds of the patients by respiratory or digestive tract infections (6) in the previous weeks to neurologic onset (4). Various infectious agents and antecedent events were suggested as trigger factors $(6,7)$. The most common infections preceding GBS are those with $C$. jejuni, cytomegalovirus (CMV), Zika virus, Epstein Barr virus (EBV), human immunodeficiency virus (HIV), Mycoplasma pneumoniae (M. pneumoniae), Hemophilus influenzae (H. influenzae) and even Coronaviridae family viruses (6,54-56). SARS-CoV-2 is closely related to SARS-CoV-1, which produced Middle East Respiratory Syndrome (MERS). Cases of GBS were reported during the MERS outbreak in 2012 and the possibility of an aetiological link between the two diseases has been raised (55). The mentioned pathogens have the ability to induce an autoimmune response that involves a mechanism of molecular mimicry between lipopolysaccharides and myelin sheath or Schwann cells, with membrane gangliosides expressed on peripheral nerve fibers $(31,56)$. Another proposed mechanism would be antibody precipitation on axons or myelin sheaths with complement activation and attack membrane formation $(34,57)$.

Given the experience of other viral pandemics, we would expect an increase in the number of case reports with peripheral nervous system damage in the context of the COVID-19 pandemic. GBS cases in the context of COVID-19 underscore the importance of testing for SARS-CoV-2 in these patients.

It is not clear whether there is a pathophysiologically related connection between SARS-CoV-2 and GBS, the biomarkers needed for diagnosis, or how viral infection influences the evolution of GBS, but in most cases, direct viral infection of the nervous system does not seem to trigger the onset of neurological disease. The clinical diagnosis is suspected based on acute motor deficit pattern, sensory and autonomic dysfunction, areflexia, or albumin cytologic dissociation, and in some cases nerve conduction studies were performed $(2,37,39)$. Possible biomarkers regarding the prognosis and therapeutic response of GBS and SARS-CoV-2 infection could be the serum and CSF level of inflammatory cytokines.

Through studies regarding the CSF and seric cytokine profile, T-cell response in SARS-CoV-2 and even morphopathological studies are needed to decode the pathophysiology of GBS in COVID-19. These studies may be useful to develop therapeutic strategies designed to block inflammatory cytokines, such as IL-6 inhibitors (tocilizumab or sarilumab) (21). Immunomodulatory therapies administered to patients with autoimmune diseases and COVID-19 may also provide useful lessons in the prognosis and course of these patients (21).

We should bear in mind the differential diagnosis with critical care neuropathy and myopathy which occurs in intensive care patients and that $18 \%$ of chronic inflammatory demyelinating polyneuropathy (CIDP) cases can start as acute-onset CIDP mimicking AIDP (58). The electrophysiological study along with CSF analysis are important for the differential diagnosis with critical care neuropathy which is an axonal neuropathy.

Neurological examination and diagnosis of neurological complications in patients with COVID-19 are important for the prompt introduction of specific treatment and an improved prognosis of the disease. There are currently no additional indications for the diagnosis and treatment of patients with GBS and COVID-19 compared with standard recognized guidelines.

Male gender and elderly patients seem to be more affected than the younger generation $(8,39)$. Whether SARS-CoV-2-associated GBS is more frequent than it was prior to SARS-CoV-2 remains to elucidated and further studies are required to include a greater number of reported cases from previous years. However, these patients remain a reality and until the immunization of the population through vaccination is achieved (59) they need proper diagnosis and treatment. Further research is needed to investigate whether there are different GBS phenotypes associated with COVID-19 by comparing with the classically post-infectious course and if there is a causality or just a coincidence between them.

\section{Conclusions}

Neurological involvement is varied in COVID-19 and GBS may be an important aspect of the disease. GBS is a common neurological disease and whether the incidence of GBS is higher in the context of SARS-CoV-2 pandemic or represents only a coincidence of overlap of two different pathologies remains to be established by subsequent analysis of available data. Nevertheless, GBS is a reality that the neurologists, infectious disease and intensive care doctors encounter in the context of COVID-19 and for which optimal therapeutic alternatives should be sought and found.

Physicians treating patients with COVID-19 should be alert to all clinical manifestations because it is a relatively new disease and many features are not yet identified.

\section{Acknowledgements}

Not applicable.

\section{Funding}

No funding was received. 


\section{Availability of data and materials}

Not applicable.

\section{Authors' contributions}

AS designed the article. BLG, SM, AS, RB, BLG, IGC, ZB, $\mathrm{CRF}$ and SA collected the related articles and analyzed the literature data. AS and $\mathrm{ZB}$ wrote and edited the manuscript. $\mathrm{RB}, \mathrm{CRF}$, and MS critically revised the manuscript. BLG, SA and SM assessed the authenticity of all the raw data. All authors have read and approved the final manuscript.

\section{Ethics approval and consent to participate}

Not applicable.

\section{Patient consent for publication}

Not applicable.

\section{Competing interests}

The authors declare that they have no competing interests.

\section{References}

1. Mao L, Jin H, Wang M, Hu Y, Chen S, He Q, Chang J, Hong C, Zhou Y, Wang D, et al: Neurologic manifestations of hospitalized patients with coronavirus disease 2019 in Wuhan, China. JAMA Neurol 77: 683-690, 2020.

2. Baig AM: Neurological manifestations in COVID-19 caused by SARS-CoV-2. CNS Neurosci Ther 26: 499-501, 2020.

3. Romero-Sánchez CM, Díaz-Maroto I, Fernández-Díaz E, Sánchez-Larsen Á, Layos-Romero A, García-García J, González E, Redondo-Peñas I, Perona-Moratalla AB, Del Valle-Pérez JA, et al: Neurologic manifestations in hospitalized patients with COVID-19: The ALBACOVID registry. Neurology 95: e1060-e1070, 2020

4. Webb S, Wallace VC, Martin-Lopez D and Yogarajah M: Guillain-Barré syndrome following COVID-19: A newly emerging post-infectious complication. BMJ Case Rep 13: e236182, 2020

5. Baig AM, Khaleeg A, Ali U and Syeda H: Evidence of the COVID-19 virus targeting the CNS: Tissue distribution, host-virus interaction, and proposed neurotropic mechanisms. ACS Chem Neurosci 11: 995-998, 2020.

6. Stoian A, Moțățăianu A, Bărcuțean L, Maier S, Bazko Z, Voidăzan S, Fărcas A and Bălașa R: Understandig the mechanism of action of intravenous immunoglobulins: A ten years experience in treating Guillain-Barré syndrome. Farmacia 68: 426-435, 2020

7. Stoian A, Motataianu A, Bajko Z and Balasa A: Guillain-Barré and acute transverse myelitis overlap syndrome following obstetric surgery. J Crit Care Med (Targu Mures) 6: 74-79, 2020

8. Finsterer J, Scorza FA and Ghosh R: COVID-19 polyradiculitis in 24 patients without SARS-CoV-2 in the cerebro-spinal fluid. J Med Virol 93: 66-68, 2021.

9. van den Berg B, Walgaard C, Drenthen J, Fokke C, Jacobs BC, van Doorn PA: Guillain-barre syndrome: Pathogenesis, diagnosis, treatment and prognosis. Nat Rev Neurol 10: 469-482, 2014.

10. Toscano G, Palmerini F, Ravaglia S, Ruiz L, Invernizzi P, Cuzzoni MG, Franciotta D, Baldanti F, Daturi R, Postorino P, et al: Guillain-Barré syndrome associated with SARS-CoV-2. N Engl J Med 382: 2574-2576, 2020

11. Gigli GL, Bax F, Marini A, Pellitteri G, Scalise A, Surcinelli A and Valente M: Guillain-Barré syndrome in the COVID-19 era: Just an occasional cluster? J Neurol 268: 1195-1197, 2021.

12. Nyati KK and Prasad KN: Role of cytokines and Toll-like receptors in the immunopathogenesis of Guillain-Barré syndrome. Mediators Inflamm 2014: 758639, 2014
13. Sun T, Chen X, Shi S, Liu Q and Cheng Y: Peripheral blood and cerebrospinal fluid cytokine levels in Guillain Barré syndrome: A systematic review and meta-analysis. Front Neurosci 13: 717, 2019.

14. Zhang HL, Zheng XY and Zhu J: Th1/Th2/Th17/Treg cytokines in Guillain-Barre syndrome and experimental autoimmune neuritis. Cytokine Growth Factor Rev 24: 443-453, 2013.

15. Li S, Jin T, Zhang HL, Yu H, Meng F, Quezada HC, and Zhu J: Circulating Th17, Th22, and Th1 cells are elevated in the Guillain-Barré syndrome and downregulated by IVIg treatments. Mediators Inflamm 2014: 740947, 2014.

16. Han RK, Cheng YF, Zhou SS, Guo H, He RD, Chi LJ and Zhang ML: Increased circulating Th17 cell populations and elevated CSF osteopontin and IL-17 concentrations in patients with Guillain-Barré syndrome. J Clin Immunol 34: 94-103, 2014.

17. Hohnoki K, Inoue A and Koh CS: Elevated serum levels of IFN-gamma, IL-4 and TNF-alpha/unelevated serum levels of IL-10 in patients with demyelinating diseases during the acute stage. J Neuroimmunol 87: 27-32, 1998.

18. Lisak RP, Skundric D, Bealmear B and Ragheb S: The role of cytokines in Schwann cell damage, protection, and repair. J Infect Dis 176 (Suppl 2): S173-S179, 1997.

19. Nyati K, Prasad KN, Rizwan A, Verma A and Paliwal VK: TH1 and TH2 response to Campylobacter jejuni antigen in Guillain-Barré syndrome. Arch Neurol 68: 445-452, 2011.

20. Press R, Deretzi G, Zou LP, Zhu J, Fredman P, Lycke J and Link H: IL-10 and IFN-gamma in Guillain-Barré syndrome. Network members of the Swedish epidemiological study group. J Neuroimmunol 112: 129-138, 2001.

21. Koralnik IJ and Tyler KL: COVID-19: A global threat to the nervous system. Ann Neurol 88: 1-11, 2020.

22. Dogan L, Kaya D, Sarikaya T, Zengin R, Dincer A, Akinci IO and Afsar N: Plasmapheresis treatment in COVID-19-related autoimmune meningoencephalitis: Case series. Brain Behav Immun 87: 155-158, 2020.

23. Zanin L, Saraceno G, Panciani PP, Renisi G, Signorini L, Migliorati K and Fontanella MM: SARS-CoV-2 can induce brain and spine demyelinating lesions. Acta Neurochir (Wien) 162: 1491-1494, 2020

24. Diao B, Wang C, Tan Y, Chen X, Liu Y, Ning L, Chen L, Li M, Liu Y, Wang G, et al: Reduction and functional exhaustion of $\mathrm{T}$ cells in patients with coronavirus disease 2019 (COVID-19). Front Immunol 11: 827, 2020.

25. Bryce C, Grimes Z, Pujadas E, Ahuja S, Beasley MB, Albrecht R, Hernandez T, Stock A, Zhao Z, Al Rasheed M, et al: Pathophysiology of SARS-CoV-2: Targeting of endothelial cells renders a complex disease with thrombotic microangiopathy and aberrant immune response. The Mount Sinai COVID-19 autopsy experience. medRxiv, 2020

26. Netland J, Meyerholz DK, Moore S, Cassell M and Perlman S: Severe acute respiratory syndrome coronavirus infection causes neuronal death in the absence of encephalitis in mice transgenic for human ACE2. J Virol 82: 7264-7275, 2008.

27. Arabi YM, Harthi A, Hussein J, Bouchama A, Johani S, Hajeer AH, Saeed BT, Wahbi A, Saedy A, AlDabbagh T, et al: Severe neurologic syndrome associated with Middle East respiratory syndrome corona virus (MERS-CoV). Infection 43: 495-501, 2015.

28. Lau KK, Yu WC, Chu CM, Lau ST, Sheng B and Yuen KY: Possible central nervous system infection by SARS coronavirus. Emerg Infect Dis 10: 342-344, 2004.

29. Andersen KG, Rambaut A, Lipkin WI, Holmes EC and Garry RF: The proximal origin of SARS-CoV-2. Nat Med 26: 450-452, 2020.

30. Uhlén M, Fagerberg L, Hallström BM, Lindskog C, Oksvoldt P, Mardinoglu A, Sivertsson Å, Kampf C, Sjöstedt E, Asplund A, et al: Proteomics. Tissue-based map of the human proteome. Science 347: 1260419, 2015.

31. Farzi MA, Ayromlou H, Jahanbakhsh N, Bavil PH, Janzadeh A and Shayan FK: Guillain-Barré syndrome in a patient infected with SARS-CoV-2, a case report. J Neuroimmunol 346: 577294 , 2020.

32. Sancho-Saldaña A, Lambea-Gil Á, Liesa JL, Caballo MR, Garay MH, Celada DR and Serrano-Ponz M: Guillain-Barré syndrome associated with leptomeningeal enhancement following SARS-CoV-2 infection. Clin Med (Lond) 20: e93-e94, 2020.

33. Juliao Caamaño DS and Alonso Beato R: Facial diplegia, a possible atypical variant of Guillain-Barré syndrome as a rare neurological complication of SARS-CoV-2. J Clin Neurosci 77: 230-232, 2020.

34. Zhao H, Shen D, Zhou H, Liu J and Chen J: Guillain-Barré syndrome associated with SARS-CoV-2 infection: Causality or coincidence? Lancet Neurol 19: 383-384, 2020. 
35. Alberti P, Beretta S, Piatti M, Karantzoulis A, Piatti ML, Santoro P, Viganò M, Giovannelli G, Pirro F, Montisano DA, et al: Guillain-Barré syndrome related to COVID-19 infection. Neurol Neuroimmunol Neuroinflamm 7: e741, 2020.

36. Sedaghat $Z$ and Karimi N: Guillain Barre syndrome associated with COVID-19 infection: A case report. J Clin Neurosci 76 233-235, 2020.

37. Tiet MY and AlShaikh N: Guillain-Barré syndrome associated with COVID-19 infection: A case from the UK. BMJ Case Rep 13: e236536, 2020.

38. Su XW, Palka SV, Rao RR, Chen FS, Brackney CR and Cambi F: SARS-CoV-2-associated Guillain-Barré syndrome with dysautonomia. Muscle Nerve 62: E48-E49, 2020.

39. Uncini A, Vallat JM and Jacobs BC: Guillain-Barré syndrome in SARS-CoV-2 infection: An instant systematic review of the first six months of pandemic. J Neurol Neurosurg Psychiatry 91: 1105-1110, 2020

40. Velayos Galán A, Del Saz Saucedo P, Peinado Postigo F and Botia Paniagua E: Guillain-Barré syndrome associated with SARS-CoV-2 infection. Neurologia 35: 268-269, 2020 (In English, Spanish)

41. Virani A, Rabold E, Hanson T, Haag A, Elrufay R, Cheema T, Balaan $\mathrm{M}$ and Bhanot N: Guillain-Barré syndrome associated with SARS-CoV-2 infection. IDCases 20: e00771, 2020.

42. Coen M, Jeanson G, Culebras Almeida LA, Hübers A, Stierlin F Najjar I, Ongaro M, Moulin K, Makrygianni M, Leemann B, et al: Guillain-Barré syndrome as a complication of SARS-CoV-2 infection. Brain Behav Immun 87: 111-112, 2020.

43. Qin J, You C, Lin Q, Hu T, Yu S and Zhou XH: Estimation of incubation period distribution of COVID-19 using disease onset forward time: A novel cross-sectional and forward follow-up study. medRxiv: 2020.03.06.20032417, 2020.

44. Wang L, Shen Y, Li M, Chuang H, Ye Y, Zhao H and Wang $\mathrm{H}$ : Clinical manifestations and evidence of neurological involvement in 2019 novel coronavirus SARS-CoV-2: A systematic review and meta-analysis. J Neurol 267: 2777-2789, 2020.

45. Helms J, Kremer S, Merdji H, Clere-Jehl R, Schenck M, Kummerlen C, Collange O, Boulay C, Fafi-Kremer S, Ohana M, et al: Neurologic features in severe SARS-CoV-2 infection. N Engl J Med 382: 2268-2270, 2020

46. Moriguchi T, Harii N, Goto J, Harada D, Sugawara H, Takamino J, Ueno M, Sakata H, Kondo K, Myose N, et al: A first case of meningitis/encephalitis associated with SARS-Coronavirus-2. Int J Infect Dis 94: 55-58, 2020.

47. Sun X, Wang T, Cai D, Hu Z, Chen J, Liao H, Zhi L, Wei H, Zhang Z, Qiu Y, et al: Cytokine storm intervention in the early stages of COVID-19 pneumonia. Cytokine Growth Factor Rev 53: 38-42, 2020.

48. Balasa R: Therapeutic plasma exchange: An indispensable therapy for severe neurological condition. J Crit Care Med (Targu Mures) 6: 89-90, 2020.
49. Abrams RM, Kim BD, Markantone DM, Reilly K, PanizMondolfi AE, Gitman MR, Choo SY, Tse W and Robinson-Papp J: Severe rapidly progressive Guillain-Barré syndrome in the setting of acute COVID-19 disease. J Neurovirol 26: 797-799, 2020.

50. Gutiérrez-Ortiz C, Méndez-Guerrero A, Rodrigo-Rey S, San Pedro-Murillo E, Bermejo-Guerrero L, Gordo-Mañas R, Aragón-Gómez F and Benito-León J: Miller Fisher syndrome and polyneuritis cranialis in COVID-19. Neurology 95: e601-e605, 2020.

51. Fantini J, Di Scala C, Chahinian H and Yahi N: Structural and molecular modelling studies reveal a new mechanism of action of chloroquine and hydroxychloroquine against SARS-CoV-2 infection. Int J Antimicrob Agents 55: 105960, 2020.

52. Duong L, Xu P and Liu A: Meningoencephalitis without respiratory failure in a young female patient with COVID-19 infection in downtown los angeles, early April 2020. Brain Behav Immun 87: 33, 2020.

53. Goldman N, Cuvellier JC, Soto-Ares G and Vallée L: A post cytomegalovirus Guillain-Barré syndrome, with atypical presentation, associated with arachnoiditis in a 10-month-old girl. Neuro Neurosurg 1: 1-2, 2018.

54. Docea AO, Tsatsakis A, Albulescu D, Cristea O, Zlatian O, Vinceti M, Moschos SA, Tsoukalas D, Goumenou M, Drakoulis N, et al: A new threat from an old enemy: Re-emergence of coronavirus (Review). Int J Mol Med 45: 1631-1643, 2020.

55. Kim JE, Heo JH, Kim HO, Song SH, Park SS, Park TH, Ahn JY, Kim MK and Choi JP: Neurological complications during treatment of Middle East respiratory syndrome. J Clin Neurol 13: 227-233, 2017.

56. Koga M: Experimental approach in research of Guillain-Barré syndrome: A range of pathogeneses mediated by molecular mimicry. Clin Exp Neuroimmunol 9: 93-100, 2018.

57. van Doorn PA, Ruts L and Jacobs BC: Clinical features, pathogenesis, and treatment of Guillain-Barré syndrome. Lancet Neurol 7: 939-950, 2008.

58. Bunschoten C, Jacobs BC, Van den Bergh PY, Cornblath DR and van Doorn PA: Progress in diagnosis and treatment of chronic inflammatory demyelinating polyradiculoneuropathy. Lancet Neuro 18: 784-794, 2019.

59. Calina D, Docea AO, Petrakis D, Egorov AM, Ishmukhametov AA, Gabibov AG, Shtilman MI, Kostoff R, Carvalho F, Vinceti M, et al: Towards effective COVID-19 vaccines: Updates, perspectives and challenges (Review). Int J Mol Med 46: 3-16, 2020.

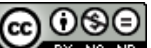

This work is licensed under a Creative Commons Attribution-NonCommercial-NoDerivatives 4.0 International (CC BY-NC-ND 4.0) License. 